\title{
Governance Issues for SMEs
}

\author{
Thomas Clarke and Alice Klettner \\ University of Technology Sydney, Australia
}

\begin{abstract}
This paper draws on research into the corporate governance practices of small and medium enterprises (SMEs) listed on the Australian Securities Exchange. Interviews were conducted with the directors and/or company secretaries of 19 SMEs. The aim of the research was to explore not only SME corporate governance structures and processes but how SMEs had chosen to implement the Principles and the reasons for their choices. The paper addresses the issue of whether the ASX Corporate Governance Principles and Recommendations were appropriate for SMEs. It describes the SME responses to the requirements, how these differ from those of larger companies, and how these differences impact on small companies.
\end{abstract}

\section{Keywords}

Small medium enterprises, governance

\section{Introduction}

The first task in writing about small to medium enterprises (SMEs) is to define the scope of the term. Most definitions seem to focus on the number of employees as a measure, sometimes also combining this with financial measures such as annual turnover or market capitalisation. In 2000, Huse reviewed research on boards of SMEs in the ten most established European-based SME journals and found a variety of employee-based definitions being used (2000:274). Of the 19 papers "about boards of directors in SMEs during the 1990s", 10 included companies with less than 50 employees, seven included companies with 50-499 employees and one included companies with more than 500 employees. Seven included discussion of SMEs without any size indications.

In its July 2000 SME strategy document the World Bank states:

"What is an SME? There is no universal definition. Some analysts use objective standards, classifying firms with fewer than 10 employees as "microenterprises", those with 10 to 100 employees as "small" and those with 100 to 500 as "medium" - or even listing any company with annual turnover below $\$ 10$ million as an SME. Others prefer to rank companies by their relative size within the local economy, since a large company in Macedonia would likely be considered small in Brazil."

Ayyagari et al have reviewed SME definitions across the world as part of their work in examining the contribution of the SME sector towards overall economic activity. They chose a cut-off of 250 employees when compiling their data tables but also provided the official SME definition for each of

Copyright (C) 2009 Victoria University. This document has been published as part of the Journal of Business Systems, Governance and Ethics in both online and print formats. Educational and non-profit institutions are granted a nonexclusive licence to utilise this document in whole or in part for personal or classroom use without fee, provided that correct attribution and citation are made and this copyright statement is reproduced. Any other usage is prohibited without the express permission of the publisher.
76 countries. They sum up the difficulties of defining an SME as follows:

"Efforts to compile data on the size of the SME sector across countries have been plagued by several problems of comparability and consistency. Different countries adopt different criteria - such as employment, sales or investment- 


\begin{abstract}
for defining small and medium enterprises. Hence different sources of information on SMEs use different criteria in compiling statistics. Even the definition of an SME on the basis of a specific criterion is not uniform across countries. For instance, a specific country may define an SME to be an enterprise with less than 500 employees, while another country may define the cut-off to be 250 employees." (2007:415-416)
\end{abstract}

The Australian Bureau of Statistics (ABS) defines a small business as one that employs less than 20 people and a medium business 20 to 200. This is on the small side compared to other countries but of course the definition varies even within each country.

The UK's Institute of Directors (IoD) defines an SME as having less than 250 employees. In their policy papers they use the definition set out by the UK Government's Department for Business, Enterprise and Regulatory Reform (DBERR) which defines micro-firms as having 0-9 employees, small firms as 10-49 employees and medium firms as 50-249 employees. The IoD points out that the European Commission, Companies Act and British Bankers Association all hold different and distinct notions of the characteristics and thresholds that constitute an SME" (Ehmann:2007).

This paper draws on our research into the corporate governance practices of companies listed on the ASX. We conducted interviews with directors and/or company secretaries of 67 listed companies, exploring not only the corporate governance structures and processes that they had chosen to implement but the reasons for their choices. We asked about the costs and benefits of complying with the ASX Principles and explored participants' views on the 'comply or explain' mechanism.

Because our research focused on listed companies, we deal in this paper with 'smaller' companies rather than the 'smallest' companies which of course will not be publicly listed. We categorised companies by market capitalization, with anything outside the ASX 300 being an SME. We did not collect information on employee numbers but in visiting the premises of these companies we could see that most had less than 200 employees. In this paper we discuss the problems faced by small to medium listed companies in complying with a 'one-size fits all" corporate governance regime often said to be better suited to large corporations.

Of course, this is a governance regime designed to protect investors who buy publicly listed shares. It is a regime predicated on the assumption of a separation between ownership and management of the company. That is, a company owned by a large number of dispersed shareholders and managed by a small team of professionals. The corporate governance provisions of the Corporations Act 2001, the ASX Listing Rules and the ASX Corporate Governance Principles and Recommendations are primarily designed to protect shareholders from any self-serving behaviour on the part of management or other major shareholders represented on the board. Thus, formally at least shareholders may elect a board to represent their interests and to monitor management. The law requires that the company establish board structures and disclose certain information in order that shareholders can be confident that their investment is being managed to an acceptable standard.

The issue considered in this paper is whether this corporate governance regime, established with larger listed corporations in mind, is appropriate for SMEs. Firstly, we need to look more closely at what the regime entails for SMEs and whether they are treated any differently from the large companies. Secondly, we draw on our research, as well as surveys completed by the ASX, to see how SMEs have responded to the new regime. We can then explore some of the reasons for the observed responses, and examine how the structure and nature of SMEs differ from larger companies. Finally we examine how these differences may impact upon the ease of implementation of corporate governance regulation. What is the effect of governance regulation on small companies? Is it achieving its purpose or having unintended adverse effects? Could we improve or simplify corporate governance for SMEs and thereby achieve a better balance between economic aims (entrepreneurship and innovation) and protective aims (promotion of investor confidence)? Can we draw on developments overseas to guide us in this process? 


\section{Corporate Governance Requirements for SMEs}

Recent corporate governance reforms in Australia, at least for listed companies, have centred around a system of 'comply or explain' similar to the UK system. The ASX Corporate Governance Principles and Recommendations (the Principles) apply to all listed companies by way of Listing Rule 4.10.3 which requires companies to disclose the extent to which they have adopted each of the 8 principles (recently consolidated from the original 10) and 28 recommendations. If a company has not adopted a particular recommendation it must explain why.

The Principles are described as a reporting framework designed to provide a "practical guide" for companies, investors and the wider market. The foreword to the first edition stated:

"The size, complexity and operations of companies differ, and so flexibility must be allowed in the structures adopted to optimise individual performance. That flexibility must, however, be tempered by accountability - the obligation to explain to investors why an alternative approach is adopted - the "if not, why not" obligation."

There was express recognition when the Principles were introduced that one size does not fit all and hence the Principles are flexible rather than being prescriptive. In a section entitled 'how to approach adoption of the best practice recommendations' (2003:5 and 2007:5) the Principles state:

"The Council recognises that the range in size and diversity of companies is significant and that smaller companies may face particular issues in attaining all recommendations from the outset. Performance and effectiveness can be compromised by material change that is not managed sensibly. Where a company is considering widespread structural changes in order to meet best practice, the company is encouraged to prioritise its needs and to set and disclose best practice goals against an indicative timeframe for meeting them."

This paragraph does not concede that any of the Principles might be inappropriate for a smaller company, only that small companies might need longer to achieve 'best practice' (more recently considered 'good practice'). The only recognition of any disconnect between the Principles and the needs of small companies (or at least small boards) is found in the commentary to the recommendations on board sub-committees: "It is recognised that for smaller boards, the same efficiencies may not be apparent from
a formal committee structure."

This sentence was changed slightly in the second edition of the ASX Principles (2007). It makes it clear that even if there is no formal sub-committee the functions that it would carry out must still be in place.

"For smaller boards, the same efficiencies may not be derived from a formal committee structure. Companies without a [nomination, audit or remuneration] committee should have board processes in place which raise the issues that would otherwise be considered by the [nomination, audit or remuneration] committee."

The only area where the ASX Principles formally distinguish between large and small companies is in the requirements dealing with the composition, operation and responsibility of the audit committee. Listing rule 12.7 requires that companies in the S\&P/ASX All Ordinaries Index (top 500) must have an audit committee and those in the top 300 must comply with recommendation 4.2 regarding the composition of that committee. Recommendation 4.2 suggests audit committees should be made up of:

- only non-executive directors

- a majority of independent directors

- an independent chairperson, who is not chairperson of the board

- at least three members.

It was recognised that this would be onerous for SMEs and hence it is only mandatory for the top 300 companies. It is perhaps significant from a policy point of view that, rather than being drafted as an 
exemption for small companies, it has been included in the Listing Rules as a mandatory requirement for large companies.

The ASX Principles are not law, and were created by the ASX Corporate Governance Council (CGC). The CGC is made up of representatives from 21 business associations representing the interests of a wide range of groups involved in the investment and governance value chain including shareholders, directors, accountants and superannuation funds. Although most of these associations consulted their members, there was no explanatory memorandum or parliamentary discussion regarding the policy decisions taken.

The ASX set up a body known as the Implementation Review Group (IRG) in mid-2003 to provide an independent review of the industry response to the Principles. The IRG was made up of a panel of senior industry practitioners, representing a cross section of the corporate and investment community, including advisors to and directors of smaller companies. The IRG's first report published in March 2003 confirmed the universal approach:
"The IRG received numerous submissions suggesting that particular classes of companies (e.g. small companies) should be exempt from the requirement to report against the Council's Recommendations. The IRG believes however, that the 10 Principles and the requirement to report against the Recommendations should apply to all listed companies, regardless of size or maturity. Exempting any class of listed company from reporting against the Recommendations would be inconsistent with the disclosure-based approach."

The document went on to explain that making exceptions would be inappropriate because the Principles do not require compliance in any event. Further, if a company has made the decision to raise money from the public it should be obliged to provide sufficient disclosure to investors to enable them to assess the quality of the company's corporate governance procedures. This is hard to argue against. The element of choice involved in listing makes it difficult to justify any sort of exemption.

Rather than recommending any significant alterations to the Principles, the IRG stressed their flexible nature. The IRG provided guidance for SMEs on how to approach some of the Principles, particularly the requirements for a majority of independent directors. It recognised that in the early stages of a company's life cycle, expertise might be more important than independence. It suggested that companies without a majority of independent directors might explain their non-compliance in terms of:

- The value to the company of the knowledge, experience or expertise of its directors given the stage of growth or nature of the company. Your board should consider providing more fulsome disclosure in relation to the skills, experience and abilities of its directors and how the company benefits from this.

- The risk profile of the company and the impact this has on desirable board membership. For example, your board may wish to discuss the entrepreneurial nature of the business.

The IRG took the stance of educating and encouraging SMEs to make use of the option of exception reporting. There was recognition that the optimal balance between objectivity of directors and their value to the company can vary over the life of a company and that certain investors might reasonably expect to have representation on the board.

The IRG's Second Report to the ASX Corporate Governance Council published in February 2005 throws further light on the thinking behind a universal set of principles. The IRG considered that the audit committee rules should not be seen as validating a move towards further exceptions:

The IRG is concerned that segmentation of the market involves a shift away from the flexibility of the current disclosure-based approach towards a more prescriptive one. The implication would be that companies above or below a certain size or of a certain business type would be expected to adopt specific Recommendations. Such a change would undermine the current emphasis on promoting 'substance over form' and carries 
the potential to reinforce a 'tick the box' approach. The IRG wishes to avoid any risk of degrading into a 'tick a box' governance environment.

In 2006 the ASX conducted a review of the Principles and in 2007 published a revised second edition. The review involved a consultation paper and opportunity for public submissions. The consultation paper stated:

"Since Council released the Principles there has been discussion about whether the Principles should be modified to assist smaller companies by providing "carve-outs" from the Principles. During its review, Council considered the possibility of modifying the Principles and Recommendations for smaller companies and has decided that the Principles and Recommendations should be the same for all listed entities. ASX conducted a market research program among Small to Medium Enterprises (SMEs) and their advisers which found that there was overall support for the Principles, while acknowledging that the independence and audit committee requirements were more difficult for this sector.

Council considers that all companies, regardless of size or industry, that have made the decision to raise capital from the public, should provide investors with sufficient disclosure to enable them to assess the quality of the corporate governance policies and processes in place in those companies in which they invest.

The revised Principles provide assistance for smaller listed companies which adopt alternative practices from those outlined in the Principles, such as removal of the phrase "best practice". Other changes include recognising that companies may use alternatives to board committees in Principles 2, 4 and 9. Council reminds smaller companies that it is entirely acceptable for them to adopt effective governance practices that differ from the Principles, provided they make appropriate disclosure."

In its response to public submissions the ASX said the following regarding the issue of SMEs:

Those submissions that addressed this issue generally expressed support for Council's decision not to provide a "carve out" from the Revised Principles for SMEs. The rationale for Council's decision is that all listed companies raise funds from the public and there should not be a differential standard of reporting. One submission raised the related point of whether "if not, why not" reporting should be required by this sector where they adopt alternative practices to those set out in the Recommendations. Council has decided not to pursue this suggestion for the reasons referred to above. (ASX, 2007, para 31)

Blakiston \& Crabb lawyers provided the submission referred to above which focused on the issues faced by SME's:
"Blakiston \& Crabb reviewed the consultative paper, liaised with a number of clients and submitted detailed comments to the ASX Council in early February 2007. Over 100 companies provided letters of support for the Blakiston \& Crabb submission.

The central theme of the submission was an attempt to improve the application of the Principles and the reporting requirements from the viewpoint of small to medium enterprises." (Zimmel, 2007)

Blakiston \& Crabb have since joined up with Deloittes and ASX Markets Supervision to produce a guide for SMEs in relation to Principle 7 on risk management as this was deemed to be another difficult area for companies at the small end of the listed scale. The introduction states:

"ASXMS has identified that small to mid-capitalised ASX-listed entities may experience difficulty in implementing risk management practices which accord with the recommendations in the Principles due to the generally lower level of resources available to such entities. The purpose of this Guide is to allow small to mid-capitalised ASX-listed entities to access information and guidance on the management of material business risks 
in a way that will allow them to report positively against the recommendations in Principle 7."

To conclude, there has been a reluctance, to date, to provide any form of exemption or alternative regime for listed SMEs. The use of a universal but flexible set of principles appears to be fairly established with no SME-specific changes made in the second edition of the ASX Principles. The provision of supplementary guidance, rather than exemptions appears to be the favoured pathway.

\section{SME Response to the Principles}

Each year since the first edition of the Principles, the ASX has carried out a review of compliance. Although these reviews have not looked specifically at the issues faced by SMEs they do provide anecdotal evidence of the widely held belief that smaller companies are more likely than larger ones to give 'why not' explanations.

The ASX's 2009 review was the first to be conducted since publication of the second edition of the Principles. At the time of the review only a small proportion of all listed companies (those with their accounting year-end in December rather than June) were reporting against the 2007 edition of the Principles, the majority still reporting against the 2003 edition. The ASX published two separate reviews for each of these sub-sets of companies. In both reviews the main comment regarding SMEs was in relation to Recommendation 2.1 which suggests boards should have a majority of independent directors. It was found that adoption of this recommendation was higher in the top-500 companies than across all companies:

The high level of "if not, why not" reporting confirms anecdotal evidence that smaller listed entities are more likely to adopt alternative board and committee structures and report on an "if not, why not" basis. The continued high rate of "if not, why not" reporting is also evidence of the ongoing acceptance and adoption of the corporate governance reporting framework outlined in the ASX Listing Rules and the Revised Principles (ASX, 2009a:16 and 2009b:14)

One of the common reasons for choosing to give a 'why not' explanation regarding independent directors was that the company or board was too small. Other interconnected reasons included the high cost of independent directors, the limited resources of the company to engage them and/or doubts that the experience and skills of non-independent directors were appropriate for the company. (ASX, 2009a:16) For end-June companies there was also found to be a high level of 'why not' reporting with regard to Recommendation 2.4 which suggests the establishment of a Remuneration Committee:

The overall reporting level for Recommendation 2.4 for listed companies saw an increase in 2008 to $98 \%$ from $90 \%$ in 2007. This result was almost entirely due to an increase in "if not, why not" reporting which rose from 58\% in 2007 to $67 \%$ in 2008. This result confirms anecdotal evidence that smaller listed entities are more likely to "if not, why not" report in relation to the Recommendations on committee composition and are comfortable with this reporting approach. (ASX 2009a:18)

This finding, of SMEs choosing not to have the recommended number of board sub-committees and/or independent directors has been consistent across all of the ASX's annual reviews. Our research throws more light on these two areas of the Principles. We will deal with each in turn, first use of board subcommittees and then the issue of independent directors.

\section{Committees}

On the issue of board sub-committees responses from the SMEs we interviewed were mixed. As might be expected from the ASX surveys several companies did not have separate nomination and remuneration committees:

We don't have a nominations committee because our board is so small it tends to be the whole board. 
We didn't see the need for a separate nomination committee. The audit committee can do it or add two more and you have the whole board

We had three committees but have now reduced it to two. The audit committee I chair and the nomination and remuneration committees have been combined into one. There was not a lot of work on the nomination side and a fair amount on the remuneration side.

Others had created these committees but only because it was easy to do so. Here we have evidence of the pressure to conform, even if doing so provides little or no value to the company:

We have set one up in order to comply because it's not difficult.

The committees are a bit of a farce for us.... The audit and risk committee is necessary, nomination and remuneration is a bit of a farce...

Yes, we have the three committees but I don't think they are really very useful for us with a small board. Three of the four directors are on each committee and the other one is generally invited.

At the other extreme we had several participants who thought the committees were a great thing even if it had taken them a while to appreciate their role:

It is fantastic having the committees both in terms of dedicated time and in developing specific expertise. From the point of view of an executive director it is terrific to have that responsibility taken away from you to someone with focus.

Yes, the committees are useful. They each met four times this year even though the remuneration and nomination committee is only supposed to meet twice.

The board formed the view at the time that there would only be an audit committee even though we were not required for a company of our size. We thought that would be quite sufficient. The last thing you want is more committees. You don't want any to be quite honest. But as we have come along, the board has seen there is a role for them and so we developed the remuneration committee with a standard charter. It has since expanded its role to remuneration and nomination.

\section{Independent directors}

The issue of independence on SME boards is often linked to the nature of the shareholder base. As will be discussed below, many SMEs are tightly held with one or more controlling shareholders who are often represented on the board. Thus, these directors, even if they are non-executives, will not be independent because of their shareholding. The requirements in the ASX Principles regarding independent directors have been one of the more controversial aspects of the Principles. Is independence being held up as more important than competence? Why should a director suddenly lose his or her independence after a certain number of years on the board? The ASX Principles suggest that a majority of board members should be independent. The first edition of the Principles provided what it called a definition of independence in Box 2.1 as follows:

"An independent director is a non-executive director (i.e. is not a member of management) and:

1. is not a substantial shareholder of the company or an officer of, or otherwise associated directly with, a substantial shareholder of the company

2. within the last three years has not been employed in an executive capacity by the company or another group member, or been a director after ceasing to hold any such employment

3. within the last three years has not been a principal of a material professional adviser or a material consultant to the company or another group member, or an employee materially associated with the service provided 
4. is not a material supplier or customer of the company or other group member, or an officer of or otherwise associated directly or indirectly with a material supplier or customer

5. has no material contractual relationship with the company or another group member other than as a director of the company

6. has not served on the board for a period which could, or could reasonably be perceived to, materially interfere with the director's ability to act in the best interests of the company

7. is free from any interest and any business or other relationship which could, or could reasonably be perceived to, materially interfere with the director's ability to act in the best interests of the company."

In response to criticism that some of these criteria were too prescriptive, the second edition has softened and removed some of the criteria as well as making it clear that they are designed to give guidance rather than a definition of independence. Box 2.1 now states:

When determining the independent status of a director the board should consider whether the director:

1. is a substantial shareholder of the company or an officer of, or otherwise associated directly with, a substantial shareholder of the company

2. is employed, or has previously been employed in an executive capacity by the company or another group member, and there has not been a period of at least three years between ceasing such employment and serving on the board

3. has within the last three years been a principal of a material professional adviser or a material consultant to the company or another group member, or an employee materially associated with the service provided

4. is a material supplier or customer of the company or other group member, or an officer of or otherwise associated directly or indirectly with a material supplier or customer

5. has a material contractual relationship with the company or another group member other than as a director.

This may make it easier for SMEs to explain why they consider a particular director to be independent despite not meeting all the criteria. Nevertheless, the ASX surveys show that many SMEs do not have a majority of independent directors. Our research supports this finding and shows that there may be two reasons for this non-compliance. Firstly, when a company first lists its board often includes some of the founding directors and/or representatives of the venture capitalists who do not want to lose control. Secondly, companies can find it hard to attract independent directors with the skills that are going to justify their directors' fees:

...for smaller companies it is difficult to comply. Often, I believe, in this sector at least, particularly at the early stages. Of course, the VC wants to keep an eye on things and is not independent and the issue of founding directors can be difficult, particularly for products that they have invented.

At the start we would have struggled to get a good person to come in. We had to prove the business model - only then can you go out and get someone who will really add value.

We do need another independent non-executive... It's the cost holding us back. They get $\$ 35,000$ a year for 12 meetings so usually it's better to get a skilled tool-maker.

However, what was perhaps more surprising was that most participants genuinely seemed to want to change this situation. They could see the value of independent directors and were striving to achieve a majority. The reasons for this will be discussed below as they are closely linked to the issue of whether there is an 'agency gap' in SMEs. 


\section{General response}

Although the ASX survey identified certain recommendations with a high level of non-compliance, the overall trend was one of widespread adoption of the Principles. Again, our research backed this up. Most SMEs limited their 'why not' explanations to those mentioned above and had complied with the remainder of the Principles.

One would hope that this compliance 'on paper' translates to some meaningful changes within the companies. Unfortunately, however, some of the recently listed participants saw corporate governance as a process of creating a swathe of policies that did not really change much within the business:

What you see in the annual report is pretty standard. What was put together at the time of the listing - articles of association, board structures and committees - was designed to tick boxes with the Guidelines.

An experienced professional director told us that this was common when companies are preparing to list:

Governance is just so far down the list in terms of the things needed to be done-road shows, brokers meetings etc that they don't really think about it. Then they find themselves saddled with a load of stuff they've not read and which they don't do. They have just thought, well, we've got to have a statement so let's buy one.

Some companies, however, were trying hard to break out of that mould and were justifying the time spent on governance as an investment for the future:

... although we are only a small business we intend to start the way we want to finish

We wanted to improve corporate governance because we wanted to grow. However I suspect we overdid it because of our big company backgrounds.

Others took the middle road, accepting that they had to create and implement appropriate policies as part of the listing process:

When you move from the small league to the big league there are certain things you've just got to do.

To be listed we had to do it all - create the corporate governance policy, board charter, committee charters etc. We took a fairly vanilla one and then adjusted it to fit our needs.

We've done it all for the first time - the present set of ASX Guidelines were around a year or two before we floated so its just been a matter of bringing the company into that scene. We've had to introduce certain disciplines to the board papers and meetings.

We implement corporate governance as far as we can without incurring cost. Where we struggle is having to do it all ourselves. It gives me more to do. Although the internet and having 100 other companies reporting first is great - the wording for policies is already set up.

This cost-benefit equation is of course the key to effective regulation and will be discussed further below. Certainly, directors of smaller organisations appear to appreciate the flexibility inherent in the ASX Principles. A submission to the ASX review from Mr Mark Beavis states:

As a Director of a medium-size credit union (total assets of $\$ 105 \mathrm{~m}$ ), I found value in the actual principles; by way of contrast, I was dismayed and annoyed when APRA released its Prudential Standard on Governance, which effectively imposes a governance structure irrespective (and possibly to the detriment) of a company's unique culture, situation and strategy.

In a similar vein, the submissions from two companies considering a listing on the ASX in future (Emerging Group Capital and Cubbie Group Limited) both stress: 
...the practical workability of the final document you produce will be a very important factor in the deliberations a company such as ours will go through in deciding whether or not to proceed to an ASX listing

Most of the participants in our research project were in favour of the 'comply or explain regime although there were some concerns over the response of investors to 'why not' explanations.

I'm a supporter of the 'if not why not' approach. As long as investors understand that there are good reason for not complying and the company is not penalised for it (e.g. independence) then I think it is appropriate in the main. If you make it too complex it's just a rod for the back.

\section{Why Should There be a Different Regime for SMEs?}

The regulation and corporate governance for Australian companies is predicated on the assumption that there is a separation between the ownership and management of the company. However, this 'agency gap' may not always arise for small companies. The real question is whether, if owners and managers are not entirely separate groups, is there a need to impose a swathe of monitoring processes or can the owners look after themselves? Is there any value for SMEs in complying with the ASX Principles?

Our research focuses on listed companies. Thus even the small companies have offered their shares to the public and there will be some level of gap between ownership and control. However, this gap can be quite different in the newly listed companies as compared to those that are well established. Often, when a company first lists many of the directors will be substantial shareholders, perhaps the original founders of the company or representatives of the venture capitalists. The share capital may be tightly held such that the top twenty shareholders make up a large proportion of the total share capital. These shareholders will be in close contact with management and therefore are likely to have a high level of awareness of the company's activities that is not necessarily enhanced by an annual corporate governance statement. There may be a controlling shareholder who sits on the board or who has great influence over the company's activities.

The theory is that when companies are tightly held like this, with several substantial shareholders, those shareholders will have an incentive to monitor the company closely thus reducing the agency problem associated with more dispersed ownership. In the participants' words:

We have a small shareholder base so I think they are all fairly aware of what's going on.

The larger shareholders talk to us directly anyway so it covers off governance [communications].

The big boys get the information they need - they will just ring the CEO.

Two or three contact me once a month for a chat. We have still got the six MBOs in the top 20 and five or six shareholders we talk to on a regular basis.

In addition to those in the annual report we make it our business to talk one on one to major shareholders on a regular basis. It is discriminatory but every company is the same - we talk regularly with our top 6-8 shareholders or any interested shareholders - those considering buying.

However, as Dallas and Scott observe, this does not mean there is no agency problem just that it is a different type of agency problem, namely "the extent to which the interests of controlling shareholders might differ from those of small shareholders" (2006, p118). This is borne out in our research, with several interviewees mentioning problems stemming from a controlling shareholder, for example:

It is hard to have a non-executive director as a shareholder. What's good for the company is not always good for a shareholder. It seems weird but it's true. For example, if we wanted to do a fund raising, we might want $\$ 6$ million to create capital reserves and the shareholder might just see the dilution and want, say, \$4 million. 
I think in this sector you often find you have one dominant founder with too much stock and a controlling interest which can be a problem.

We have five non-execs but one is not independent. He owns $55 \%$ of the issued capital so if he wants to be Chairman, he will! It's deemed one of the corporate governance nasties. He was MD at one stage too and that does cause problems occasionally.

This suggests that monitoring by substantial shareholders is not the answer. In fact, it demonstrates the importance of independent directors who will take into account the interests of all shareholders as a group. In contrast to some of our interviews with larger corporations, there appeared to be overwhelming support for independent directors from most SME participants. They were seen as vital if quality decisions were to be made:

Yes, we did go looking for independent directors. [One] left and all three remaining were non-independent. So there were not enough directors because there were a lot of issues where the two major shareholders were involved. There was a real need for more - we were getting desperate because we just couldn't take decisions. It was not just about compliance.

I'd prefer to see all independents other than the executives. I much prefer people without interests. You get better decisions out of the board.

As soon as you are not just looking after your own money you've got problems if there is no independence.

In micro-caps like us that are recently listed, you'll find we are entrepreneurial businesses that have been given life by one or two individuals. Not surprisingly those individuals are quite mercurial in foreseeing business opportunities but not that au fait with corporate law and governance etc. There can be interesting dynamics in governance, between personalities. Having independent directors that are experienced in public companies is very important.

To some extent, the debate on independent directors revolves around the role of the board in SMEs. Corporate governance requirements such as the ASX Principles are designed to facilitate the monitoring role of the board. The argument is that this monitoring role is not important where shareholders are few and in close contact with management. So, if the monitoring role of the board is less important in SMEs, what is the board's role?

This is an area where academic research is still in its infancy (van den Heuvel et al, 2006, p.468). In 2000 Morten Huse set out a review and research agenda for boards of directors in SMEs on the basis that prior research was fragmented, a view that probably still holds true. Nevertheless, there seems to be some consensus that, like most boards, there are two main roles for SME boards: control and service. Van den Heuvel et al explain that, "the control role is mainly based on agency theory, whereas the service role embraces several theoretical perspectives" (2006, p.481). Primarily, the service role emphasizes the board's function as a source of counsel and advice as well as a link to external resources through connections and networks. Pugliese raises a third strategic role which could perhaps be included within the service role (2006). It comprises the role of the board in setting the strategic context and direction of the business.

Our research supports these different roles. Participants spoke positively about the discipline that the board as a whole exerted over the key executives but were also very aware of the skill set of their board in terms of the services members could provide. Those boards that were looking for additional members were very clear about the skills, knowledge and/or connections that they hoped to gain from a new director:

Our only weakness is the non-executives. We do need another independent non-executive with device experience... Really we want someone US-based too because most of our trading is there.

I'd say we do need someone from Queensland Inc... it pays to be inside the loop. 
None of the SMEs were concerned about their board members having too many other directorships. They were more likely to be concerned about directors not having enough. The experience and connections gained from those other directorships was seen as very valuable:

It would be a concern if, for example, our founding [director] was approached by a competitor but outside of that it is seen as valuable. It gives us an understanding of the workings of other boards and how they approach things, for example, a fund-raising. It gives us contacts if we need them.

Interestingly, Van den Heuvel et al find that CEOs tend to view the service role of their board as more important than the control role (2006, p.479). Thus, we can see how some CEOs may resist the introduction of independent directors if it means they will lose a trusted, long-term board advisor. Participants commented:
If you go back to the role of a board at a high level and think where it should be spending its time - in my view it is there to help the CEO succeed and to represent the shareholders as they would expect, rather than as dictated by regulators... What we are seeing with boards currently is that they don't understand that that is their role. They too often revert to process.

The board is used as a sounding board by the CEO and myself. Its role is to challenge what we are doing...

What we really want to know is whether any aspect of the boards' role is of greater significance in SMEs than in large enterprises. If so, does corporate governance regulation support or impede directors in carrying out that role? Pugliese gets to the nub of the issue with the comment:
...it is becoming increasingly common to see reforms in the corporate governance domain calling for an increasing number of outsiders or independent directors on boards also in small firms; but it seems that the rule-makers do not take into account the different characteristics of these firms, by simply copying a reform-scheme which applies to listed companies without any changes despite their diversities.

Pugliese's research finds that the most important features affecting the strategic role of the board in SMEs are the qualitative attributes of the board members such as industry knowledge, diversity of background and personal motivation (2006 p.51). He finds it paradoxical that these are the only attributes that are not ruled upon or defined by norms and codes (2006, p.51).

Lynall et all take a wider approach to the issue of board roles by looking at the way in which board composition can change over the company life-cycle (2003). They conclude that the composition of the board at formation will depend on the relative power of the CEO and financiers as well as the stage of the organizational life-cycle within which the company finds itself $(2003, p .427)$. Some boards are formed when the company is still in the entrepreneurial stage, others are formed later when the company is becoming more complex and is starting to introduce a more formalised structure. Lynall et al argue that the role of the board will vary as the company moves through these stages and its composition will reflect that role. They would agree that agency theory and the monitoring role of the board is less important in the early stages of the company life-cycle.

\section{Cost}

The Australian Government's Regulatory Taskforce's January 2006 report Rethinking Regulation heard much evidence from small business that red tape is absorbing time and energy and becoming a drag on entrepreneurial drive (p5). In summary (pii):
"The costs of regulation to business involve not just extra time, paperwork and capital outlays, but also deflect management from the core activities of the business. Submissions indicated that compliance matters can consume up to $25 \%$ of the time of senior management and boards of large companies. The impact is even greater for small businesses, which generally do not have the in-house capacity to deal with and keep 
abreast of the regulatory morass. Regulation can thus stifle innovation and crowd out productive activity in the 'engine room' of Australia's economy."

Of course, this report was dealing with all regulation rather than just corporate governance requirements but the point made about the impact on small business may still be valid. Eric Mayne, a member of the ASX Corporate Governance Council, stated in a speech in November 2005 that the CGC was looking into whether corporate governance reporting could be made simpler for smaller listed companies. This was because:
"The costliness of compliance with the Corporate Governance Council principles and recommendations was another issue that emerged from our discussions with industry participants."

However, there have not been any concrete suggestions as to how costs could be reduced for SMEs. It was implied in the speech that perhaps SMEs did not fully understand the inherent flexibility of the Principles and needed to be educated on how they could make use of the 'why not' option. Following the IRG's second report, specific guidance on exception reporting was published in the form of examples. However, company representatives say that the pressure to comply does not come from the regulation, rather from the investors and rating agencies that fail to properly engage with exception reporting.

Importantly, our research to date does not provide strong support an argument that corporate governance regulation is unreasonably costly for SMEs. This may be a consequence of our methodology and/or the relatively small size of our SME sample. It could also be a result of the fact that putting a dollar cost on corporate governance is extremely difficult in any size of organization (Chittenden et al, 2002). As the quotes below demonstrate nearly all participants said that the greatest cost had been in terms of time. As most of our interviewees held the position of company secretary, this often equated to their own time.

The costs I couldn't identify but they are not high. More effort has been put into drafting the website disclosures but no wholesale training has been required. The cost has been in time more than anything else.

Time. We've not used any externals because we were tight on cash but it's taken up a lot of my time. I've got more people in my team now but I don't think that's because of governance - just because we've grown - although it does assist.

It's not been a great cost other than my time. I got some assistance from my mates in accounting firms - templates etc - which doesn't cost us anything.

Certainly there have been no major external costs. A little on the legal side - sub $\$ 10,000$ which we could have put to better use

Thus the costs are internal and hard to quantify. Several company secretaries commented that the most significant cost to the company was their salary, some had been employed specifically for the job although most also had another role within the company, commonly CFO.

Next to costs, I wrote my name! They have had to employ me as a part-time company secretary... and it has taken up time for [the executive directors].

One participant noted that because of the increasing governance workload, it was becoming more common for SMEs to employ a governance specialist:

There seems to be a flip when a company gets to a certain market cap they employ a specialist company secretary. That line is moving down-CFOs just can't handle both.

This kind of employment cost should not be underestimated for a recently listed company. It can be costs such as these that restrain newly listed companies in appointing more than a minimum of board members. Also, the significance of any expenditure on employees and/or direct costs will depend on how well the company is doing financially: 
There is a significant cost associated. The costs are principally, my salary. I don't do only corporate governance, I am involved in strategy too. They can't afford for me to do corporate governance alone. There is a direct cost for the functions I have to do: disclosure, holding AGMs, publishing the annual report. I don't know how many dollars but for a company that has not yet made any profit or paid a dividend it's a significant cost.

However, the recently listed companies tended to include the cost of corporate governance in the overall cost of choosing to list. Several interviewees commented that listing was an extremely expensive way to raise money and only worth considering when all other options had been exhausted:

It is becoming increasingly difficult to say that there's value in being listed when you are a micro-cap. The liquidity of stock and access to capital is more illusory than real. There is a significant dollar cost and resource cost in that you loose the time of your senior people worrying about governance when they should be focused on the business.

I've said to others, if you don't need to list then don 't - it's not glamorous. You do it to raise money to continue operations or for some specific purpose or as an exit strategy. Otherwise it is a lot of cost for no value.

\section{Benefits}

The greatest benefit for SMEs in implementing corporate governance procedures appeared to be the enforcement of discipline on directors who were very much used to doing things their own way. One participant described the change as a "cultural revolution" that had been quite awkward for some of the original founding directors. Most said it had led to a much higher level of professionalism and better decision-making processes:

It gives the shareholders comfort and it is useful for the board to have the guidelines, e.g. for trading shares. They have that framework to refer to. The directors can't say, I didn't know I couldn't do that.

Certainly it has introduced discipline - a more disciplined approach to decision-making - which is a benefit to the company. We have had to drag [the founders] into it - there is a monthly battle over the board reports but we eventually get them. Where everyone is an employee you set the deadline and they meet it but here there is still an owner-mentality.

Effectively there's an awareness that was always underlying but has now been made more visible. It's now something you can refer to - label things as governance whereas before they would be just an ethical issue. It has formalised what we would have done anyway-you are forced to think twice.

Being listed is certainly a function of moving from a cosy environment of investors on the board doing as they please into a level of professionalism.

Of course, corporate governance regulation has a dual purpose. As well as improving the running of companies it is designed to protect ASX investors. The maintenance of investor confidence is vital to the sustainability of the ASX as a market and thus will benefit the companies indirectly. It is perhaps because of this indirect nature of the benefits that several participants found it harder to identify the value of the procedures they had implemented:

There is not a lot [of benefit] for people who take their fiduciary duties seriously. Your gut tells you if you are on the right track or not-you don't need a 20 page document.

There are not too many [benefits], I guess. I really do see it as a compliance exercise.

There was never a real issue.

\section{UK Developments}

Can we draw on developments overseas in assessing the appropriateness of the Australian regime? The UK is often the first port of call because it has a similar system based on 'comply or explain' 
disclosures. A number of the provisions of the UK's Combined Code do not apply to 'smaller companies'. For the purposes of the Code a smaller company is one that was below the FTSE 350 throughout the year immediately prior to the reporting year. The exemptions are not extensive. In summary, the board of a smaller company need only have two independent directors rather than a majority. This means that the audit and remuneration committees need only be made up of two independent directors rather than three. However, the introduction to the Code expressly recognises that SMEs may find some provisions inappropriate:

Smaller listed companies, in particular those new to listing, may judge that some of the provisions are disproportionate or less relevant in their case. Some of the provisions do not apply to companies below the FTSE 350. Such companies may nonetheless consider that it would be appropriate to adopt the approach in the Code and they are encouraged to consider this. Investment companies typically have a different board structure, which may affect the relevance of particular provisions.

In September and October 2006, the UK's Financial Reporting Council (FRC) conducted interviews with over 40 chairs of FTSE 250 and small-cap companies regarding the impact of the Combined Code. Not surprisingly, the issue of cost was raised:
It was widely felt that the costs of complying with the Code were proportionately higher for FTSE 250 and smaller companies than for the FTSE 100, and that this was exacerbated by the comparative difficulty in persuading investors to engage in dialogue which left these companies feeling under pressure to comply. (Financial Reporting Council, 2006)

In the UK, much like in Australia, it has been observed that companies can feel pressured by investors to comply with the Code rather than explain their non-compliance. This is because they feel that investors are taking a tick-box approach to compliance and not taking the time to read, engage and understand their explanations. This leads to a perception at the FRC that the rules themselves are not flawed, instead market participants' response to them (particularly rating agencies and institutional investors) is the problem. If small companies felt free to explain their non-compliance, this would keep costs to a minimum.

This issue was also raised in a 2005 review of the UK Code. Although the review did not recommend any changes to the Code to relieve the burden on SMEs, the issue of compliance costs for smaller listed companies was to be kept under review. Thus, the issues of cost and the effectiveness of the comply and explain system were again put forward for consultation in the 2007 review:
The FRC recognizes that the potential compliance costs are proportionately higher for smaller companies, particularly bearing in mind the possible frustrations of "comply or explain" referred to above. If these are considered to outweigh the benefits associated with the Code, there may be an argument on regulatory impact grounds for some modification to what is required from smaller companies. On the whole, the 2006 consultations with the Chairs of smaller companies were not compelling on the point, but the sample was small and continuing open-mindedness on the FRC's part is appropriate. (Financial Reporting Council, 2007)

Despite this, the 2007 review did not result in any SME-specific changes and the issue has been somewhat overshadowed in the 2009 review by the global financial crisis and its implications for corporate regulation as a whole.

\section{US Developments}

In the US the Sarbanes-Oxley Act of 2003 (SOX) was introduced in response to the collapse of huge firms such as Enron and Worldcom. Its most notorious provision was Section 404 requiring management assessment of internal controls. SOX is often described as a hasty over-reaction to the events of the early 2000s and because it is much less flexible than the reforms of Australia and the UK it is also seen as being much more expensive, especially for SMEs. Kamar et al explain: 


\begin{abstract}
"Small firms may incur relatively higher SOX-related compliance costs for a number of reasons. First, they may experience a disproportionately large increase in audit fees because some of the costs associated with establishing, maintaining, and evaluating internal controls over financial reporting are fixed and because small firms often lack the staff to perform in-house the additional accounting work" (2009:9).
\end{abstract}

The lack of in-house staff also means that small firms struggle to respond to complex standards and tend to require more guidance than their larger counterparts. In the case of the SOX internal control provisions the SEC issued final rules in June 2003 but did not release interpretive guidelines until May 2007 (Kamar et al, 2007:9).

Although audit costs are the most prominent issue for SMEs, several other issues have been raised:

One concern is that some of the new rules make it difficult for firms to attract individuals to serve as directors because they increase liability exposure and tighten independence standards. This concern might be greater in the case of small businesses because serving on their boards is less prestigious. Consistently, Linck, Netter, and Yang (2007) find that, after the enactment of SOX, director fees as a percentage of net sales increased significantly more for small firms than for large ones. Another concern is that preoccupation with compliance discourages taking business risks. This can be especially problematic for small firms at the start of their growth." (Kamar et al, 2007:10)

Empirical work on the issue is most readily available regarding the issue of audit costs"

"Several studies compare SOX costs of small and large firms. They report that Section
404 implementation costs comprise a larger percentage of revenues for small firms, and
that this percentage declined between the first year and the second years after the
enactment of SOX for both small and large firms." (Kamar et al, 2007:12)

Interestingly, however, these studies also showed that even before the passage of SOX audit costs were disproportionately higher for SMEs. Nevertheless, this disparity did increase after SOX's enactment.

As in other countries the issue of regulatory costs for SMEs has been considered by the supervisory authorities. In April 2006 the SEC issued a report recommending scaling down the requirements under Section 404 for firms whose stock market capitalization is between \$128 million and \$787 million ("Smallcap firms"), and further scaling down these requirements for firms whose stock market capitalization is less than $\$ 128$ million ("Microcap firms"). Like in Australia and the UK, carve-outs for SMEs were rejected in favour of better guidelines and a postponement of implementation.

\title{
Policy Conclusions
}

This survey of the regulation of corporate governance in SMEs highlights a number of policy conclusions:

- The need for corporate governance guidelines to include flexibility, particularly for companies early in their life-cycle.

- The need to reinforce the robustness of the "if not-why not" approach and educate the market that disclosure, not uniformity, is important.

- The fact that corporate governance demands upon companies develop as they increase in scale and complexity with more diffuse shareholders

- The existence of a critical period in corporate governance when private companies become listed entities with wider accountability and a corresponding need for a more independent board.

- The importance of legal and regulatory guidance and director education for companies preparing to list.

- The fact that companies may carry with them problems of inadequate corporate governance and dysfunctional boards if these are not resolved early in the company life-cycle. 


\section{References}

Aggarwal R. and Williamson R. Did New Regulations Target the Relevant Corporate Governance Attributes, Working Paper, 14 April 2006 available at http://papers.ssrn.com/sol3/papers.cfm?abstractid=891411

Australian Stock Exchange, (2003) Principles of Good Corporate Governance and Best Practice Recommendations, March 2003

Australian Stock Exchange (2007) Corporate Governance Principles and Recommendations $2^{\text {nd }}$ Edition, ASX Corporate Governance Council

Australian Stock Exchange (2006) Review of the Principles of Good Corporate Governance and Best Practice Recommendations: ASX Corporate Governance Council Explanatory paper and Consultation paper, 2 November 2006

Australian Stock Exchange (2007) ASX Corporate Governance Council Response to Submissions on Review of Corporate Governance Principles and Recommendations, August 2007

Australian Stock Exchange (2009a) Analysis of Corporate Governance Disclosures in Annual Reports for the year ended 20 June 2008 available at

http://www.asx.com.au/about/corporate governance/monitoring compliance.htm

Australian Stock Exchange (2009b) Analysis of Corporate Governance Disclosures in Annual Reports for the year ended 31 December 2008 available at

http://www.asx.com.au/about/corporate governance/monitoring compliance.htm

Australian Stock Exchange, Blakiston \& Crabb Lawyers and Deloitte (2009) "Principle 7: Recognise and Manage Risk: Guide for small-mid market capitalised companies, June 2009 available at http://www.blakcrab.com.au/article.asp?ArticleID=536

Ayyagari M., Beck T., Demirguc-Kunt, (2007) A. Small and Medium Enterprises Across the Globe, Small Business Economics 29:415-434

Bainbridge S. (2002) The Board of Directors a Nexus of Contracts Iowa Law Review 88, 1.

Chittenden F., Kauser S. and Poutziouris P. (2002) Regulatory Burdens of Small Business: A Literature Review, Manchester Business School

Dallas G. S. and Scott H. S. (2006) Can one set of rules fit all? Mandating Corporate Behaviour, The Corporate Governance Law Review Vol 2, No 2, 117-144

Financial Reporting Council, (2006) FRC Meetings with the Chairs of FTSE 250 and Small Cap Companies: Summary of Discussions, November 2006, available at http://www.frc.org.uk/corporate/combinedcode.cfm viewed 6 May 2007

Financial Reporting Council (2007) Review of the Impact of the Combined Code, April 2007

Gabrielsson J. and Winlund H. (2000) Boards of directors in small and medium sized industrial firms: examining the effects of the board working style on board task performance, Entrepreneuership and Regional Development 12(4), 311-330

Huse M. (2000) Boards of directors in SMEs: a Review and Research Agenda Enrepreneurship and Regional Development 12(4), 271-290

Kamar E., Karaca-Mandic P. and Talley E. “Sarbanes-Oxley's Effects on Small Firms: What is the Evidence?" Harvard Law School John M. Olin Center for Law, Economics and Business, Discussion Paper No. 588, July 2007

Linck, James, Jeffry Netter and Tina Yang, 2005, Effects and unintended consequences of the Sarbanes-Oxley Act on corporate boards, Working Paper, University of Georgia

Lynall M. golden B. and Hillman A., Board Composition from Adolescence to Maturity: A Multitheoretic View.

Pettigrew, A.M. (1992) On Studying Managerial Elites, Strategic Management Journal, 13, 163-182

Pugliese, A. (2006) Determinants of Board Strategic Involvement in Small Firms: an Empirical Analysis of Norwegian Companies Best paper proceedings from the EURAM Boards and governance track in Oslo 2006, 37-54

Romano, Roberta, 2005, The Sarbanes-Oxley Act and the making of quack corporate governance, Yale Law Journal 114, 1521-1611

Securities and Exchange Commission, 2006, Final Report of the Advisory Committee on Smaller Public Companies to the U.S. Securities and Exchange Commission, April 23, 2006, Washington, DC. 
Van den Heuvel J., Van Gils A. and Voordeckers W. (2006) Board Roles in Small and Medium-Sized Family Businesses: performance and Corporate Governance Vol 14, No 5, 467-485

Zimmel, H. ASX Review of Corporate Governance, Blakiston \& Crabb Lawyers, 3 May 2007 available at http://www.blakcrab.com.au/article.asp?ArticleID=436\&Status=archive 